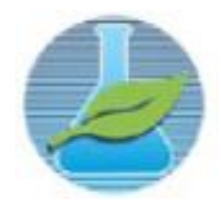

JCEC/REQ ${ }^{2}$

Journal

ISSN: 2446-9416

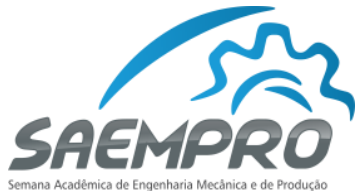

"EU, A INDÚSTRIA E O MUNDO"

08 a 11 de novembro de 2016 no campus Viçosa da UFV

Departamento de Engenharia de Produção e Mecânica - DEP

Universidade Federal de Viçosa - UFV

\title{
ESTUDO DE VIABILIDADE TÉCNICA, ECONÔMICA E COMERCIAL E DO IMPACTO AMBIENTAL E SOCIAL PARA O DESENVOLVIMENTO DE UM SOFTWARE
}

\author{
Nathalia Zandomingo Silvestre, Adriana Ferreira de Faria \\ Departamento de Engenharia de Produção e Mecânica, Universidade Federal de Viçosa \\ Rua dos Passos, 19/305 - 36570-000 - Viçosa - Minas Gerais \\ zandomingo.nathalia@gmail.com
}

\section{INTRODUÇÃO}

O ambiente mercadológico atual vem apresentando novos perfis consumidores, mais críticos em relação a um melhor custo-benefício de produtos e/ou serviços. Ao almejar o sucesso neste contexto de mercado, as empresas necessitam de ferramentas capazes de atribuir uma vantagem competitiva em relação a seus concorrentes. Essas ferramentas, alinhadas com o ambiente externo, auxiliam na formulação de estratégias para o proveito máximo das oportunidades identificadas no mesmo.

No Brasil, os potenciais empreendedores tecnológicos estão, em sua maioria, dentro das universidades (Drummond, 2005). Tendo isso em vista, as spin-offs acadêmicas (SOA) se destacam no contexto citado, já que o processo de criação dessas empresas tem como base pesquisas, infraestrutura e recursos oriundos de universidades.

Segundo Cheng et al. (2007), para auxiliar na consolidação desses novos empreendimentos, é necessário englobar políticas, programas de incentivos e suporte técnico. Com esse objetivo, órgãos institucionais internos - Escritórios de transferência de tecnologia que auxiliam na proteção e fomento do processo do produto/serviço; Incubadoras de Empresas que oferecem estruturas gerenciais e físicas; e Parques Tecnológicos que estabelecem um ambiente favorável para o lançamento das empresas no mercado - vêm sendo implementados com uma maior frequência para promover a criação de novas SOA.

Diante disso, é possível perceber que uma alternativa natural é que as empresas de base tecnológica possam ser criadas e desenvolvidas em um ambiente que favoreça o desenvolvimento de suas competências, tornando-as sustentáveis e competitivas num cenário nacional e internacional. É necessário oferecer às empresas infraestrutura educacional e científica, mecanismos de apoio à inovação e cooperação tecnológica e estratégias empresariais. Este ambiente pode ser oferecido através das incubadoras de empresas (Faria et al., 2008).

\section{OBJETIVOS}

Este trabalho teve por objetivo desenvolver o Estudo de Viabilidade Técnica, Econômica, Comercial e de Avaliação dos Impactos Social e Ambiental de Softwares (EVTECIAS) do Sistema de Gerenciamento de Bares e Restaurantes da Empresa THERIONTEC SISTEMAS INOVADORES, incubada na Incubadora de Empresas de Base Tecnológica do Centro de Desenvolvimento Regional da Universidade Federal de Viçosa (CENTEV/UFV).

\section{METODOLOGIA}


A metodologia empregada no trabalho foi determinada a partir do objetivo do mesmo. Foram consideradas as seguintes etapas para a conclusão do EVTECIAS:

A. Revisão de Literatura - consulta a livros, artigos, teses, dissertações e documentos eletrônicos nas áreas da pesquisa;

B. Diagnóstico Inicial da Empresa - reuniões e questionários direcionados à coleta de informações;

C. Coleta de Informações - pesquisas relacionadas ao desenvolvimento dos tópicos do EVTECIAS;

D. Elaboração do EVTECIAS - junção de todo o trabalho realizado anteriormente.

Então, o trabalho pode ser classificado como Pesquisa-Ação em que os integrantes da situação investigada são, ao mesmo tempo, objetos de estudo e participantes da resolução dos próprios problemas (Coughlan e Coughlan, 2002).

\section{RESULTADOS}

Para o desenvolvimento da pesquisa foi utilizado o modelo EVTECIAS com enfoque em softwares, que adequa as particularidades do desenvolvimento de softwares em ENBT's ${ }^{1}$ às ferramentas disponíveis para a avaliação de viabilidade. O modelo encontra-se estruturado em: viabilidade técnica, mercado, empreendimento e conclusões.

\subsection{Viabilidade Técnica}

No primeiro tópico do EVTECIAS foi apresentada uma visão geral da tecnologia a ser desenvolvida. Com isso busca-se compreender se é possível desenvolvê-la.

Em seguida tratou-se da proteção intelectual do software descrevendo os passos que foram ou serão dados pelos empreendedores para garantir a dita proteção junto ao Instituto Nacional da Propriedade Industrial (INPI).

Além disso, esquematizou-se o estágio de desenvolvimento da tecnologia, contemplando as etapas de transição da ideia de implementação até a comercialização efetiva do software, para que sejam identificadas possíveis barreiras para a efetivação desta tecnologia e com isso sejam propostas estratégias para a sua transposição.

A última etapa deste tópico apresentou as equipes técnica e gerencial relacionadas ao projeto, a qual apresentou as competências da equipe para o desenvolvimento e conclusão do projeto com sucesso.

\subsection{Mercado}

O segundo tópico do modelo reuniu informações relativas ao mercado no qual o programa será inserido. Foi realizado um levantamento das oportunidades de negócio que resultou em um mapeamento com as possíveis aplicações daquele programa.

A etapa seguinte diz respeito às regulamentações, órgãos regulamentadores, legislações vigentes e certificações relacionadas aos mercados vislumbrados e também quais são as tendências futuras da evolução dessas regulamentações na área.

Ainda, procedeu-se à caracterização geral do mercado e seu futuro, com o intuito de diminuir as incertezas do projeto. O levantamento das necessidades dos clientes é um ponto importante para o planejamento da qualidade do produto. Em seguida trabalhou-se a relação de forças, esclarecendo a relação do projeto com os concorrentes, fornecedores, clientes, substitutos, novos entrantes e complementadores. Esta etapa teve a função de estabelecer um cenário na qual a tecnologia será implantada, para que dessa forma possam ser elencadas ações para a inserção desta no mercado.

\footnotetext{
${ }^{1}$ Empresas Nascentes de Base Tecnológica
} 


\subsection{Empreendimento}

O terceiro tópico do modelo utilizado avaliou questões em níveis estratégicas com o levantamento dos fatores internos (forças e fraquezas) e externos (oportunidades e ameaças) em torno do projeto, e também elaborando as estratégias comerciais que devem ser adotadas pela empresa para que sejam potencializadas as oportunidades e minimizadas as ameaças.

\subsection{Conclusões}

Nesta etapa, usando-se como base as informações e análises desenvolvidas nos tópicos anteriores, procedeu-se à conclusão de viabilidade quanto aos fatores técnicos, comerciais, financeiros e econômicos, bem como os impactos ambientais e sociais do projeto. Destaca-se que na conclusão financeira foi apresentado ainda um conjunto de indicadores econômico-financeiros que podem auxiliar os empreendedores na tomada de decisão, bem como ser utilizado para apresentação da tecnologia para possíveis investidores.

\section{CONCLUSÃO}

A partir da realização deste projeto foi possível perceber que o EVTECIAS contribui efetivamente para a análise da viabilidade de novos softwares de uma forma mais impessoal, reduzindo as incertezas e aumentando a consistência das informações, dando à empresa a chance de melhorar sua capacidade de inovar, lançando produtos com rapidez e qualidade.

Em relação ao modelo proposto, atendeu as particularidades e necessidades da ENBT estudada e seu projeto, sendo adaptado ao contexto da empresa, já que o modelo pode ser aplicado ao caso de novos softwares.

Dessa forma, sugere-se que, em trabalhos futuros, ocorra uma investigação da flexibilidade do modelo para uma melhor adaptação às particularidades de cada projeto, resultando em uma melhor abrangência das pesquisas e aumentando as chances de sucesso no mercado.

\section{REFERÊNCIAS}

CHENG, L. C.; MELO FILHO, L. D. R. QFD. “Desdobramento da função qualidade na gestão de desenvolvimento de produtos". São Paulo: Editora Blucher, 2007.

COUGHLAN, P.; COGHLAN, D. "Action research for operations management". Int. Journal of Operations and Production Management, Vol. 22 No 2, p. 220-240, 2002.

DRUMMOND, P. H. F. "O Planejamento tecnológico de uma empresa de base tecnológica de origem acadêmica por intermédio dos métodos technology roadmapping (TRM), technology stage-gate (TSG), e processo de desenvolvimento de produtos (PDP) tradicional”. 2005. Dissertação (Programa de Pós-Graduação em Engenharia de Produção) - Universidade Federal de Minas Gerais, Belo Horizonte. 2005.

FARIA, A. F. "Editorial: Tecnologias de Gestão e Inovação Organizacional". Informativo Incubadora. Ano 1, n. 3. Viçosa: Centev/UFV, 2008.

Incubadora de Empresas de Base Tecnológica CENTEV/UFV. Disponível em: <www.centev.ufv.br/incubadora/>. Acesso em 25/07/2013.

LEONEL, S. G. "Um estudo do processo de planejamento tecnológico de uma empresa nascente: alinhando tecnologia, produto e mercado com foco na necessidade do cliente". 2007. Dissertação (Programa de Pós-Graduação em Engenharia de Produção) - Universidade Federal de Minas Gerais, Belo Horizonte. 2007.

MONTGOMERY, C. A. \& PORTER, M. E. "Estratégia: a busca da vantagem competitiva". Rio de Janeiro: Campus, 1998.

PLONSKI, G. A. “Cooperação Universidade-Empresa: um Desafio Gerencial Complexo”. Revista de Administração da USP (RAUSP), Vol. 34, 1999.

TAKAHASHI, S.; TAKAHASHI, V.P. Gestão de inovação de produtos: estratégia, processo, organização e conhecimento. Rio de Janeiro: Campus, 2007. 
THIOLLENT, M. Metodologia da Pesquisa-ação. 14ed. São Paulo: Cortez, 2005. 